Goldschmidt 2021 Abstract

https://doi.org/10.7185/gold2021.5978

\section{Strontium and sulphur isotope variations in the Flatreef on Turfspruit and Macalacaskop, northern lobe, Bushveld Complex: Correlation with the Upper Critical Zone - Main Zone transition \\ JARLEN KEET ${ }^{1}$, FREDERICK ROELOFSE ${ }^{1}$, CHRISTOPH GAUERT $^{1}$ AND DANIE GROBLER ${ }^{2}$ \\ ${ }^{1}$ University of the Free State \\ ${ }^{2}$ Ivanplats (Pty) Ltd \\ Presenting Author: beukesj@ufs.ac.za}

The Platreef is the main host of PGE mineralization in the northern lobe of the Bushveld Complex (BC). It has long been suggested that the Platreef is a correlate of the Merensky and Bastard Cyclic units of the western and eastern lobes of the BC. Evidence in support of this correlation has been difficult to establish due to the heterogenous and variable nature of the Platreef along strike. The more recent discovery of the Flatreef, interpreted as the down dip, sub-horizontal extension of the Platreef, provides an exciting opportunity to study a magmatic stratigraphy less affected by footwall interaction. Here, we report Sr-isotopic compositions of plagioclase as well as $\mathrm{S}$ isotope $\left(\delta^{34} \mathrm{~S}\right)$ compositions of whole rocks through two intersections of the Flatreef and its foot and hanging walls as intersected by boreholes UMT-276 (120 m) and UMT-393 (280 m) drilled on the farms Turfspruit and Macalacaskop. The $\delta^{34} \mathrm{~S}$ values in the hanging wall ranging between 6 and 17\%o and certain layers in the Footwall Cyclic Unit ( $\delta^{34} \mathrm{~S}$ up to $18,6 \%$ ) are thought to be indicative of progressive assimilation of sedimentary/evaporitic $\mathrm{S}$ from the footwall. The Merensky Reef analogue of the Flatreef displays mantle-like S isotope signatures (-0,96-2,24\%o) similar to that of the Merensky Reef in the western and eastern BC. The variation in the Sr-isotopic composition of plagioclase and the $\mathrm{An} \%$ of plagioclase across the stratigraphic units of the Flatreef [1] (Fig. 1) in the northern lobe suggests the sequence to be a correlate of the Upper Critical Zone - Main Zone transition inclusive of the Merensky and Bastard Cyclic units in the rest of the $\mathrm{BC}$.

[1] Beukes, Roelofse, Gauert, Grobler \& Ueckermann (2021) Mineralium Deposita 56, 45-57
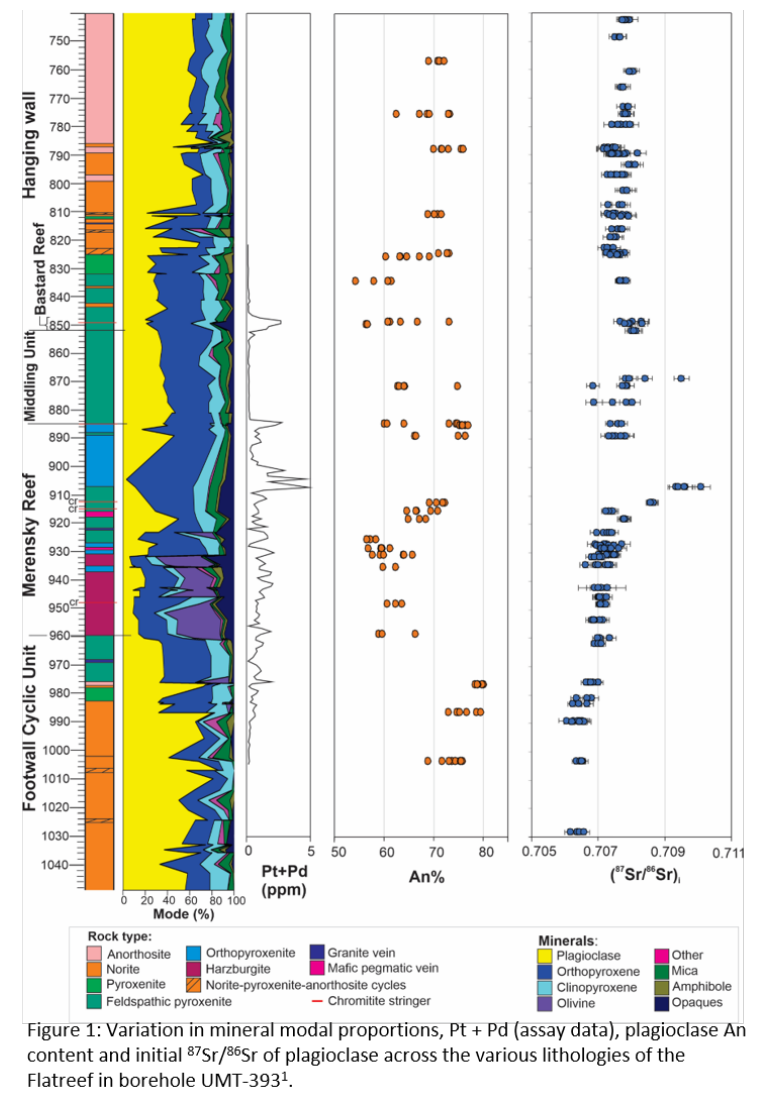
Flatreef in borehole UMT- $393^{1}$. 